\title{
BANGUNAN MIMPI TOKOH UTAMA DALAM NOVEL SELEMBAR ITU BERARTI KARYA SURYAMAN AMIPRIONO
}

\author{
Nurliawati Dide, Sugiarti \\ Pendidikan Bahasa Indonesia \\ FKIP Universitas Muhammadiyah Malang \\ didewatiy@gmail.com
}

\begin{abstract}
ABSTRAK: Penelitian ini mengangkat latar belakang permasalahan ekonomi yang dimiliki oleh tokoh utama yaitu, Putri dan Diaz. Putri dan Diaz yang harus berusaha sendiri untuk bertahan hidup dan membiayai pendidikan mereka. Lembar demi lembar kertas yang sudah tidak terpakai, di tempat tumpukan sampah dikumpulkan mereka untuk bisa bersekolah. Lika-liku perjuangan menuju sekolah yang penuh perjuangan, sera Ibu mereka yang harus bekerja dengan keadaan sakit-sakitan, sedangkan Ayah mereka yang telah lebih dulu meninggal. Akan tetapi, hidup kedua kakak beradik tersebut lebih berat, ketika ditinggal oleh kedua orang tuanya. Permasalahan ini yang mengakibabtkan, mimpi tokoh utama harus belajar bertahan hidup, kerja keras, dan terus mengejar impian. Untuk mengungkap permasalahan tersebut maka, metode yang digunakan adalah teori mimpi psikologi Sigmund Freund. Tujuan dari penelitian: (1) Tokoh utama yang ingin mendapatkan kehidupan yang lebih layak; (2) mendapatkan penghasilan untuk membiayai pendidikan; (3) menjadi orang yang pekerja keras dan pantang menyerah. Simpulan dari penelitian: (1) mimpi dari tokoh utama; (2) faktor mimpi tokoh utama; (3) dampak mimpi tokoh utama dalam kehidupan.
\end{abstract}

KATA KUNCI: Mimpi, pendidikan, kerja keras

\section{THE DREAM BUILDING OF THE MAIN CHARACTER IN THE NOVEL OF THE SHEET MEANS THE WORKS OF SURYAMAN AMIPRIONO}

\begin{abstract}
This research raises the background of economic problems that are owned by the main characters, namely, Putri and Diaz. Putri and Diaz who have to try themselves to survive and pay for their education. Sheet after sheet of paper that is not used, they collect in the trash pile to be able to go to school. The twists and turns of the struggle to school are full of struggles, as their mother has to work sickly, while their father has died earlier. However, the lives of the two siblings were tougher, when their parents left them. This problem causes the main character's dream to learn to survive, work hard, and continue to pursue dreams. To solve this problem, the method used is Sigmund Freund's psychological dream theory. The objectives of the research are: (1) the main character who wants to get a more decent life; (2) earn income to finance education; (3) become a hard worker and never give up. Conclusions from the study: (1) the dream of the main character; (2) the main character's dream factor; (3) the impact of the main character's dream in life.

KEY WORDS: Dreams, education, hard work

\begin{tabular}{lccc}
\hline Diterima: & Direvisi: & Disetujui: & Dipublikasi: \\
2020-12-03 & 2020-12-22 & $2021-01-07$ & $2021-03-28$ \\
& & \\
Pustaka & Dide, N., \& Sugiarti, S. (2021). BANGUNAN MIMPI TOKOH UTAMA DALAM NOVEL \\
SELEMBAR ITU BERARTI KARYA SURYAMAN AMIPRIONO. Fon : Jurnal Pendidikan \\
Bahasa dan Sastra Indonesia, 17(1), 42-51. doi:https://doi.org/10.25134/fjpbsi.v17i1.3725 \\
\hline
\end{tabular}
\end{abstract}

\section{PENDAHULUAN}

Pada setiap kehidupan seseorang pasti memiliki sebuah mimpi, cita-cita, impian, dan juga harapan yang melekat pada setiap manusia. Orang akan melakukan sesuatu hal yang dianggap itu akan mempengaruhinya dalam mengejar mimpi tersebut. Mimpi setiap orang tentu berbeda-beda, bagaimana cara mereka mengejar mimpi tersebut dan dari latar belakang kehidupan maupun keseharian yang berbeda pula. Latar belakang yang dimaksud adalah keseharian yang dilakukan baik dari segi tingkah laku dan juga kebutuhan ekonomi yang dimiliki. Setiap mimpi akan terwujud apabila 
ditunjang dengan kerja keras, berusaha, bersabar, berdoa dan langkah berikutnya yaitu dengan bertawaqal kepada Allah SWT. Membangun mimpi tidak hanya sekedar menata atau membuat rancangan, tetapi membangun mimpi harus dengan tekat dan niat yang sangat kuat karena hal tersebut merupakan sebuah struktur untuk membangun masa depan yang lebih baik. Seperti halnya sebuah bangunan rumah tentunya memerlukan dasar yang kuat dan tiang yang kokoh agar tidak mudah diterjang oleh angin. Mimpi tidak mudah diwujudkan dengan halnya sebuah keinginan kesenaangan untuk mengkhayal belaka. Umat manusia sejak berabad-abad yang lalu telah memberi arti penting pada mimpi dan menganggapnya sebagai nilai praktis. Artinya mereka menjadikan mimpi sebagai alat meramalkan masa depan dan mencari isyarat atau pertanda dalam mimpi (Nur, 2014: 179).

Mimpi berisi harapan atau cita-cita masa depan yang ingin dicapai oleh seseorang. Oleh karena itu, setiap orang ingin mewujudkan impian tersebut harus mempunyai bangunan mimpi atau rancangan mereka. Ketika, bangunan yang dibangun itu memiliki dinding dan atap yang kokoh, dapat disimpulkan bahwa bangunan mimpi seseorang akan senantiasa berjalan sesuai dengan apa yang diharapkan. Seperti, halnya definisi bangunan menurut ensiklopedia bangunan yang berdiri tergak, terdiri atas dinding dan atap yang berfungi untuk melindungi manusia dari cuaca, keamanan, tempat tinggal, privasi, tempat menyimpan barang, dan tempat bekerja, dengan adanya bangunan dapatmemberikan rasa aman dan nyaman pada manusia.

Pengarang mendeskripsikan kisah perjuangan kakak beradik Putri dan Diaz dalam menjelankan hidup mereka tanpa kedua orang tua. Kakak beradik yatim dan piatu yang rela melakukan apapun untuk mencari pekerjaan yang halal, agar mereka bisa bertahan hidup. Pengarang senatiasa memberikan sajian cerita, dengan mengangkat perjuangan seorang Kakak yang bernama Putri, memiliki latar belakang siswi Sekolah Dasar, yang harus bekerja demi mendapatkan penghasilan untuk pendidikan dan biaya kehidupan sehari-hari. Sebagaimana yang telah dipesankan Ibunya sebelum meninggal bahwa, mereka harus tetap bersekolah karena dengan cara seperti itu, hidup mereka akan lebih baik dari sebelumnya terutama mengangkat derajat orang tua dan mempunyai kehidupan yang lebih layak. Mengingat pesan yang disampaikan oleh Ibunya rasa ingin mengejar serta mewujudkan mimpi tersebut dengan semaksimal mungkin. Sifat yang dimiliki tokoh utama Putri dan Diaz yang mempunyai kehidupan yang serba kekurangan sehingga membuat tokoh utama harus mencari buku dari tumpukan sampah. Buku-buku bekas yang telah dibuang, terdapat lembaran halaman yang masih kosong sehingga, dapat dipergunakan mereka untuk menulis pelajaran di Sekolah, tidak hanya itu sajian pengarang pada novel ini sangat menarik untuk dibahas karena perjuanagan tokoh utama, yaitu Kakak beradik Putri dan Diaz yang tetap berusaha keras meskipuntokoh Putri yang harus tetap mengejar pelajaran dengan meminjam buku catatan temannya untuk tidak ketinggalan pelajaran di sekolah. Tekat yang dimiliki tokoh utama Putri dan Diaz pada novel Selebar itu Berarti karya Suyaman Amipriono yang digambarkan pengarang memberikan kesan bahwa, membangun mimpi itu penting dalam sebuah kehidupan untuk masa depan yang lebih baik kedepannya.

Penelitian terdahulu yang relefan dengan penelitian ini, dilakukan oleh Ambaryani (2018) "Mimpi tentang masa depan dalam karya Anak-Anak Kubu" yaitu hasil penelitian membahas tentang bentuk impian anak-anak yang tinggal di daerah terpencil, yaitu daerah yang 
dulunya pernah menjadi terkenal dan mengapa mereka menyebutkan cita-cita tersebut. Dan ternyata walaupun letak daerahnya terpencil tidak sedikitpun meredupkan semangat mereka. Nur (1875-1961) "Metafisika Mimpi, Telaah Filsafati Terhadap Teori Mimpi E.G. Jung" dalam hasil kajiannya menurut Jung mimpi merupakan gabungan antara dunia dan alam spritual atau religius. Jung mengakatan bahwa alam mimpi merupakan sebuah bentuk atau hal-hal yang disakralkan oleh manusia sebagai kehidupan dunia. Assagaf, Galib dan Wahid (2018) "Sumber Mimpi dalam PerspektifHadis" dalam hasil kajiannya membahas tentang sebuah mimi terbagi menjadi 3 benuk yaitu 1. Mimpi yang datangnya dari yang berupa kabar gembira Allah, 2. Mimpi yang mengenai omongan diri sendiri, dan 3. Kehwatiran dari Syaitan. Mimpi tidak hanya sebagai bentuk bunga tidur dari seseorang, melainkan mimpi itu adalah sebuah bentuk petunjuk, peringatan bahkan kabar gembira yang datang dari Allah SWT. Tetapi mimpi juga bisa datang karena pengaruh syaitan yang ingin menganggu manusia, mempengaruhi manusia sehingga membuat kekhawatiran, bersedih bahkan sampai sakit. Yuminah (2018) "Konsep Mimpi Dalam Perspektif Psikologi Islam: Studi Komparasi Psikologi Islam Dan Psikologi Barat" hasil kajianya adalah terdapat tiga simpulan dalam penelitiannya yaitu (1). Mimpi terbagi menjadi dua bentuk yaitu mimpi karena pengaruh psikis dan juga mimpi yang datang dari Allah SWT sebagai pertanda wahyu, peringatan sebagai bentuk untuk mengahadapai permasalahan yang di masa depan, ujian keimanan, bahkan sebagai kabar kembira dari Allah SWT. (2). Mimpi yang sangat mempengaruhi manusia dalam bentuk psikis dan juga fisik manusia. (3). Mimpi yang dialami oleh manusia mempengaruhi mental dan tingkah laku atau perilaku dari manusia.

Perbedaan penelitian ini dengan penelitian terdahulu adalah kelebihan tokoh utama yang digambarkan pengarang dari novel Selembar itu Berarti karya Surmana Amipriono digambarkan bangunan mimpi yang sebelumnya belum pernah dikaji dalam peneletian terdahulu. Bangunan mimpi seseorang itu berbedabeda dikareakan latar belakang kehidupan sehingga faktor untuk membangun mimpi serta bentuk-bentuk untuk mewujudkan mimpi pun berbeda. Penelitian ini menarik untuk dikaji karena latar belakang tokoh utama yang sangat berusaha keras untuk mewujudkan mimpi tersebut. Mengalahkan segala ego yang dimiliki, meluangkan waktu, pikiran serta tubuh untuk lebih bekerja keras agar bangunan mimpi tersebut tidak roboh melainkan terus mengalami penigkatan. Tokoh utama yang gigih dalam mewujudkan mimpi sehingga tidak mempedulikan yang lain kecuali mimpinya tersebut. Putri dan Diaz menganggap mimpi tersebut bukan sekedar khayalan yang dimilikinya sekarang tetapi, sebuah bentuk untuk bagaiaman mimpi tersebut dapat tersampaiakan dan terwujudkan di kehidupan nyata.

Persolan mimpi sering dialami oleh manusia, namun mimpi dapat ditelusuri melalui kajian psikologi sebagiamana yang dikemukan oleh Sigmund Freund. Mimpi menurut Sigmund Freund ada dua bagian yaitu, isi manifes dan isi laten. Isi manifes adalah gambaran hasil penyamaran yang dilakukan oleh cara kerja mimpi. Selain itu, terdapat visualisasi, figurasi, simbolisasi dan dramatisasi. Mimpi merupakan wujud konflik psikis bawah sadar.

Mimpi juga menjadi agen pergulatan berbagai psikis yakni id, ego dan super ego. Id merupakan motivator primer, seprti rasa lapar, haus dan seks. Prinsip kenikmatan yang dialami untuk 
tujuan yaitu mencapai kepuasan kemudian. Id bergerak berdasarkan dorongan kesenangan yang dirasakan oleh manusia. Manusia pada dasarnya ingin selalu melakukan hal-hal yang menyenagkan untuk dirinya. Memberikan kesenangan dan memanjakan diri merupakan faktor yang timbul dan selalu hadir pada setiap individu. Akan tetapi, individu yang pandai menguasai diri, akan mampu mengatur diri untuk mencari kesenangan yang bermanfaat.

Psikis kedua yaitu ego, ego berada diantara id dan super ego. Tarik menarik antara id dan super ego inilah yang menjadi pergulatan psikis yang dialami oleh individu. Oleh karena itu, tugas utama ego adalah menjebatani id dan super ego. Ego lebih kepada kehidupan nyata yang dihadapi oleh individu. Aktivitas ego sering mengalami sadar, prasadar, dan tidak disadari oleh individu. Ego yang harus dimiliki dalam diri individu seperti sebuah mimpi yang harus diperjuangan dan di raih, contohnya dalam novel ini adalah mimpi untuk tetap menjalankan pendidikan, walaupun dalam keterbatasan ekonomi yang dialami tokoh utama. Hal seperti inilah yang mendorong individu agar menjadi individu yang tetap tatat terhadap diri sendiri tanpa harus menuruti kesenangan diri semata.

Selanjutnya, psikis ketiga super ego, yaitu wujud nilai yang bersumber dari orang tua. Pengaruh orang lain dapat memberikan psikis individu menjadi berubah atau terganti. Dorongan dari super ego akan menjadikan psikis individu menjadi meningkat pula (Destari, 2008: 22-23). Super ego juga berfungsi untuk mengontrol ego pada individu, super ego akan selalu bersikap kritis kepada ego itulah, super ego banyak tak jarang menghantam serta menyerang ego. Super ego dan ego mempunyai kaitannya dengan id. Id akan dipengaruhi oleh super ego dan ego yang senantiasa hadir dan memberikan pengharapan pada diri manusia.

Terdapat beberapa cangkupan proses atau pekerjaan mimpi: figurasi dan kondensasi. Figurasi adalah bentuk untuk mewujudkan mimpi tersebut memerlukan beberapa cara tertentu, agar hasrat atau keinginan seseorang dapat terlakasana dalam bentuk aktual dan nyata. Kondensasi adalah mengabungkan beberapa pemikiran yang mendorong terjadinya mimpi. Proses ini menimbulkan hasil terwujudnya sebuah mimpi dengan dorongan orang lain. Mimpi yang berhubungan dengan pemikiran bermakna tersebunyi yang berupa bentuk analogis (Minderop, 2010).

Tujuan dari penelitian ini mendeskripsikan: (a) mimpi tokoh utama dalam novel Selember itu Berarti karya Suryaman Amipriono; (b) faktor-faktor yang menyebabkan mimpi tokoh utama dalam novel Selember itu Berarti karya Suryaman Amipriono; (c) dampak mimpi dalam kehidupan tokoh utama.

\section{METODE}

Jenis penelitian ini adalah deskriptif kualitatif, yaitu hasil analisis yang menunjukan fenomena-fenomena yang ada menggunakan kata-kata, tanpa adanya unsur statistik (Qur'aini, 2019: 13). Adapaun wujud data dalam penelitian ini berupa kutipan pada novel Selembar itu Berarti. Sumber data yang digunakan sebagai kajian penelitian adalah Selembar itu Berarti karya Suryaman Amipriono.

Teknik pengumplan data antara lain: membaca novel, memahami isi novel, menandai kutipan yang menjadi permasalahan dalam novel. Teknik analisis data pada penelitian; mengidentifikasi data, menganalisis data permasalahan dalam novel Selembar itu Berarti karya Suryaman Amipriono dan menulis hasil penelitian yang dikaji. Pengecekan keabsahan data dengan cara melakukan diskusi bersama dengan dosen 
mata kuliah dalam rentan waktu 1 bulan agar menunjukan bahwa penelitian serta kajian ini dapat dipercaya dan dipertanggung jawabkan.

\section{HASIL DAN PEMBAHASAN}

Mimpi tokoh utama, Putri dan Diaz dalam novel Selembar itu Berarti karya Suryaman Amipriono, yang mengisahkan tentang perjuangan Kakak beradik yang umurnya masih sangat muda untuk menghasilkan uang demi biaya pendidikan dan kebutuhan hidup sehari-hari. Psikis kakak beradik, yang harus melawan id, demi menjalankan ego mereka untuk tetap melanjutkan pendidikan terdapat pada hasil di bawah ini. Pergulatan psikis dan ego yang tinggi terpancar pada tokoh utama.

\section{Keinginan Tokoh Utama Untuk Melanjutkan Pendidikan}

Kehidupan tokoh utama yang serba keterbatasan dikarenakan Kakak beradik yang sudah tidak mempunyai orang tua. Pergulatan ego Putri dan Diaz yang ingin tetap melanjutkan pendidikan. Sehingga, membuat mereka harus berusaha keras untuk menghidupi diri mereka sendiri. Tidak hanya untuk makan sehari-hari tetapi, untuk melanjutkan pendidikan pun mereka harus berkerja sendiri. Seperti pada kutipan yang berada dibawah ini.

"Kicauan burung
bersangkutan, menyambut
mentar yang kian cerah
dengan sinar jingganya. Putri
dan Diaz bergegas ke sekolah.
Langkah-langkahr kecilnya
mulai menyusuri lapisan bumi
yang bergelombang"

(Amipriono, Hlm. 19).

Keterbatasan ekonomi Putri dan Diaz, akan tetapi, mereka tetap saja meneruskan pendidikan, karena mimpi yang sangat dinginkan oleh tokoh utama Putri dan Diaz adalah melanjutkan pendidikan. Mereka sangat bersemangat untuk ke sekolah, dengan langkahlangkah yang membuat mereka . Ego tokoh utama, Putri dan Diaz yang ingin melanjutkan pendidikan, senantiasa mengalahkan id mereka untuk tidak terbatas hanya sebetas mimpi akan tetapi, mimpi yang harus direalisasikan. Mereka percaya bahwa dengan pendidikan akan membuat hidup mereka menjadi lebih baik dari sebelumnya. Seperti pendapat (Sadulloh, 2012) menyatakan bahwa mereka percaya bahwa pandangan mengenai pendidikan memiliki kualitas yang dapat dijadikan tuntutan hidup. Oleh karena itu, itulah kenapa tokoh utama memiliki mimpi untuk meneruskan pendidikan, karena pemikiran dan pandangan mereka adalah untuk menemukan kehidupan yang lebih layak.

"Memang begitulah
seharusnya. Demi pendidikan,
apapun harus dilakukan.
Termasuk jika harus
memisahkan seluruh garam
yang ada di lautan. Seperti
yang dilakukan Pak Lingga,
Diaz akan dijemput hari ini.
Kabar itu disampaikan
melalui Bu Imah, kemarin
sore, sehari setelah Putri
mendapat kata setuju dari
Diaz" (Amipriono, Hlm. 115)

Mimpi tokoh utama adalah melanjutkan pendidikan. Kondisi ekonomi yang terbatas karena, sudah tidak memiliki orang tua sehingga, mengharuskan Putri harus bekerja agar bisa memenuhi kebutuhan dirinya dan juga adiknya Diaz. Akan tetapi, pekerjaan menjadi seorang penjual koran belum cukup dalam memenuhi kebutuhan mereka, apalagi harus membiayai sekolah Diaz. Oleh karena itu, Putri tidak melanjutkan sekolahnya 
karena harus bekerja. Id seorang anak yang masih berada di jenjang SD, tentu memiliki keinginan untuk tidak bekerja, tidak memikirkan hal-hal yang harusnya belum dipikirkan olehnya di masa anakanak, dan tidak ingin berpisah dari adiknya sendiri akan tetapi, karena permasalahan kebutuhan ekonomi sehingga, mengharuskan Putri harus melawan id tersebut. Merelakan Diaz yaitu adiknya sendiri untuk diadopsi oleh keluarga yang lebih mampu dalam urusan ekonomi. Putri dan Diaz yang harus menahan perasaan sedih karena harus berpisah dalam waktu yang lama, hal ini sejalan dengan pendapat Chaplin (Yurdik, 2011: 61) yang menyatakan bahwa perasaan merupakan kedaan yang timbul akibat stimulus yang diberikan baik secara internal maupun eksternal.

Faktor mimpi tokoh utama dalam novel Selembar itu Berarti karya Suryaman Amiprion adalah Tokoh utama yang mengalami persoalan ekonomi, sehingga membuat mereka harus bekerja demi mendapatkan uang untuk biaya pendidikan. Putri dan Diaz yang masih duduk di bangku Sekolah Dasar harus merasakan, perjuangan mengumpulkan uang. Akan tetapi, mimpi merupakan gambaran hasil penyamaran yang dilakukan agar tercapai mimpi seseorang. Kondensasi, merupakan gabunagn pemikiran yang mendorong terjadinya mimpi, proses seperti inilah yang akan menimbulkan hasil, tercapailah mimpi seseorang.

\section{Dorongan dan Motivasi dari Orang Tua}

Pengaruh ekonomi yang semakin melemah ketika, Ayah mereka meninggal dunia. Ditambah dengan kondisi Ibunya yang sudah dalam keadaan sakit-sakitan sejak meninggalnya Ayah mereka. Inilah yang membuat kehidupan ekonomi keluarga menjadi keterbatasan. Ibu yang harus bekerja sendiri dalam keadaan badan yang sudah tidak sehat lagi. Akan tetapi, terus memberikan dorongan untuk anak-anaknya, agar tetap bersemangat untuk mengejar mimpi mereka.

Seperti pada kutipan di bawah ini.

"Setelah Diaz mengumpulkan kertas berkas buat sekolah ya, Pak. Kertas yang ada di buku Diaz sudah hampir habis. Kakak nggak punya uang untuk membeli buku yang baru”, jawab Diaz sembari berlalu. Dia berlari-lari kecil mendekati ke arah pemulung yang berkerumunann. Truk penganggkut sampah bersiap bongkar muatan di situ. (Amipriono, Hlm. 56-57).

Sosok tokoh utama Diaz yang sudah tidak mempunyai uang untuk membeli buku sehingga, Dia harus mencarinya di tumpukan sampah. Sikap yang dilakukan Diaz menunjukan bahwa, semangatnya untuk tetap belajar dan mengejar impian dengan mencari buku-buku bekas. Akan tetapi, dengan keadaan tersebut tidak meruntuhkan semangat untuk tetap melanjutkan pendidikan. Perilaku yang dilakukan Diaz merupakan suatu dorongan dari dalam dirinya sendiri, yaitu keinginan yang ingin dicapai olehnya untuk tetap belanjutkan sekolah, meskipun dengan keterbatasan ekonomi. Adanya dorongan dalam diri manusia untuk berbuat, memenuhi kebutuhan hidupnya disebut sebagai motif. Hal ini dapat dikatakan motif karena sebagai kekuatan yang ada dalam diri manusia yang menyebabkannya bertingkah atau berbuat untuk memenuhi kebutuhannya ataupun mencapai tujuan tertentu. Motiv lebih menekankan pada dorongan internal individu (Yudrik, 2011). Keadaan seperti ini seperti halnya Diaz yang rela mencari buku bekas ditumpukan sampah demi melawan id dengan memenihi kebutuhan 
ego untuk menjadi super ego yaitu tercapainya mimpi.

“Tapi, kalian harus ingat ya.
Apa pun keadaanya.
Bagaimanapun kondisinya,
kalian tetap sekolah, ya.
Belajar yang tekun. Jaga
semangat. Bersikap disiplin.
Pantang menyerah. Agar
kalian bisa menjadi orang
yang sukses...., ucap Hera
lembut menasehati Diaz.
Tatapannya yang sejuk
memancarkan rasa kasih
sayang yang mendalam.
Membuat Diaz tak ingin
berpisah jauh dari Ibunya.
(Amipriono, Hlm. 36).

Pada kutipan di atas menggambarkan orang tua yang senatiasa memberikan motivasi kepada Kakak beradik Putri dan Diaz untuk tetap bersekolah, karena faktor dorongan dari orang tua akan menambahkan semangat pada Putri dan Diaz. Motivasi yang diberikan bersifat memberikan semangat ke arah untuk mencapai tujuan tertentu dan dalam jangka waktu yang lama (Santrock, 2008). Perhatian orang tua dengan memerikan motivasi akan lebih menbah tingkat semangat dan percaya diri seorang anak. Dengan orang tua yang harus bekerja demi menghidupi anaknya untuk tetap bersekolah itu pun merupkan dorongan yang baik untuk psikis seorang anak. Jika orang tua atau guru memberikan motivasi yang baik kepada seorang anak, itu akan menimbulkan dorongan dan hasrta untuk meljar yang lebih pada diri anak. Anak tersebut dapat menyadari apa gunanya belajar dan apa tujuan yang ingin dicapai, apabila diberi perangsang dan motivasi yang baik itu (Purwanto, 2007). Seperti halnya Hera ibu nya Putri dan Diaz yang memberikan motivasi dan semangat kepada mereka untuk tetap bersekolah, rajin, tidak pantang menyerah agar menjadi orang yang sukses.

Dalam mimpi seorang individu tentu terdapat dampak yang dialami dalam dirinya, baik positif maupun negatif. Salah satu dampak yang dialami oleh tokoh utama, Putri dan Diaz dalam novel ini adalah usaha, kerja keras, ulet serta tidak pantang menyerah yang digambarkan dalam diri mereka. Figurasi, merupakan bentuk mewujudkan mimpi, dan setiap mimpi memiliki beberapa cara dalam mewujudkannya. Salah satu perwujudan mimpi tokoh utama dengan cara usaha mencari lembar demi lembar kosong yang sudah bekas untuk tetap bersekolah.

Kerja Keras Tokoh Utama yang Mencari Lembaran Kertas untuk Bersekolah

Kondisi tokoh utama yang sangat gigih dalam meraih mimpi yang dimilikinya. Kakak beradik Putri dan Diaz yang selalu meluangkan waktu mereka untuk berusaha demi melanjutkan mimpi yaitu mimpi untuk menlanjutkan pendidikan atau tetap bersekolah. Kondisi ekonimi yang serba kecukupan sehingga perlu adanya kerja keras yang lebih lagi oleh Kakak beradik tersebut. Seperti pada kutipan yang berada di bawah ini.

"Ketika Ia melihat sebuah buku tulis yang menggenang di sungai kecil, Diaz berusaha keras untuk mengambilnya. Padahal lokasinya sulit dijangkau.

"Ih .... kayanya itu buku ya," gumam Diaz saat melihat buku bersampul merah mengambang di permukaan sungai.

"Muda-mudahan halamanya masih banyak yang kosong, jadi masih bisa diguanakan." 
Ia melepas sepatu dan kaus kaki putihnya, lalu turun dengan perlahan.

Ada beberapa undakan anak tangga yang pada sisi tebing menuju tepi sungai.

"Duuuh, curam banget," gerutu Diaz saat melewati anak tangga yang permukaannya terjal dan licin. Dia melangkah hati-hati saat turun. Tangganya berpaut apa saja untuk dipegang, termasuk tumpukan rumput dan akar pepohonan dan menyembul" (Amipriono, Hlm. 26-27).

Kerja keras kakak beradik Putri dan Diaz yang rela mencari buku bekas dan lembaran-lembaran buku yang masih kosong untuk mereka agar tetap menulis pelajaran di sekolah. Karena bersekolah tidak hanya duduk dan mendengarkan pelajaran tetapi, harus menulis setiap hal yang penting yang diberikan guru, dengan menulis juga sebagai bahan belajar untuk di rumah. Menurut Bimo (Cita, 2012: 3) mengakatan bahwa sarana dan alat penunjang kegiatan belajar adalah berupa ruang belajar anak, seragam sekolah, buku-buku, dan alatalat belajar yang lain. Untuk itu Putri dan Diaz mencari lembaran buku yang masih kosong sebagai penunjang belajar mereka di sekolah. Walupun harus mencarinya di tumpukan sampah, kerena keterbatasan biaya maka, hal tersebut harus dilakukan oleh mereka berdua.

"Putri dan Diaz memang berhasil menemukan lokasi favorit baru. Di lokasi itu, mereka banyak menemukan lebaran-lembaran kertas kosong yang bisa digunakan untuk menganggantikan buku tulis baru.
Lokasi favoritnya itu: tempat pembuangan akhir sampah yang jauh dan sumpek, yang kotor dan bau.

Bagaimanapun kotornya, Putri dan Diaz menganggap tempat itu sebagai sumber 'harta karun' yang baru karena memiliki cadangan kertas yang banyak.

Sampah kertas dari buku tulis, bagi Putri dan Diaz, bagaimana pun pasti berguna. Bagaimana yang telah ditulis mengandung ilmu, sedangkan yang belum ditulis untuk mendapatkan ilmu" (Amipriono, Hlm. 23-24).

Putri dan Diaz selalu menggangap bahwa tempat sampah adalah lahan harta bagi mereka, karena di dalamnya mereka bisa mendapatkan buku-buku bekas yang sudah tidak terpakai lagi. Buku yang masih memiliki halaman kosong di dalamnya bisa dibuat mereka untuk menulis pelajaran sekolah. Kerja keras mereka untuk mendapatkan buku-buku agar tetap, menulis ilmu yang di dapatnya selama bersekolah adalah suatu bentuk usaha yang dilakukan oleh kakak beradik ini. Ego kakak beradik ini cukup bersar dalam mewujudkan mimpi mereka, keinginan untuk tetap melanjutkan pendidikan meskipun dalam keterbatasan ekonomi. Oleh karena itu ego berperan memerintah, mengantur, dan mengendalikan kepribadian (Yudrik, 2019). Ego yang mengendalikan semua bentuk keinginan dalam diri individu.

\section{KESIMPULAN}

Mimpi merupakan sesutau yang pasti ada dalam diri setiap individu. Individu yang ulet serta tekun dalam menjalankan hidup tentu akan mendapakan apa yang sudah menjadi mimpinya. Psikis yang dialami seseorang 
berebeda-beda, ada yang sering menuruti id mereka, ada juga yang tetap mempertahankan ego yang dimiliki, bahkan bisa berubah menjadi super ego yang mendorong terjadinya peribahan perilaku yang terjadi pada diri individu.

Pada hasil dan pembahasan tersebut mimpi tokoh utama adalah menlanjutkan pendidikan. Putri dan Diaz melawan id mereka, untuk tidak bermainmain di rumah seperti anak-anak seusianya. Mereka harus bekerja agar bisa membiayai sekolah dan bertahan hidup, dikarenakan mereka sudah tidak memiliki kedua orang tua, timbah lagi mereka masih duduk di Sekolah Dasar, dengan keadaan tersebut. Terjadilah pergulan psikis pada diri Putri dan Diaz, karena mereka harus melawan $i d$, yaitu kesenangan diri yang menjadi dasar dari setiap individu, untuk tetap melaksankan ego, kemaupan atau keinginan sebenarnya dalam diri mereka untuk tetap menjalankan dan meneruskan pendidikan. Mimpi ini yang benar-benar tertanam dalam diri Putri dan Diaz.

Faktor yang mendorong terjadinya mimpi kakak beradik, Putri dan Diaz tentu ada, tentunya dorongan dari orang tua, teruama Ibu, sebelum Ibu mereka meninggal dunia. Ibunya selalu memberikan motivasi atau dorongan agar mereka tetap bersemangat untuk bersekolah atau melanjutkan pendidikan, tidak pantang menyerah dengan kedaan yang ada, yaitu kondisi mereka yang terbatas akan ekonomi. Kondensasi serta stimulus yang diberikan oleh Orang Tua membuat mereka sangat bersemangat untuk melanjutkan pendidikan dan tetap bertahan hidup. Sehingga mimpi yang selama ini di ingin oleh Putri dan Diaz tetap terwujud.

Prosess mimpi seseorang akan mempengaruhi tingkah laku atau perilaku individu, karena seiring berjalannya waktu dengan mimpi-mimpi yang berada dalam benak seseorang, maka orang tersebut akan merubah tingkah laku yang dimiliki. Perubahan yang dialami tentu karena adanya pengaruh psikis. Psikis akan mengalami perubahan karena terjadinya emosi yang timbul dari individu. Keinginan agar mimpi yang diinginkan terwujud atau terrealisasikan di kehidupan nyata. Untuk mewujudkan mimpi tersebut terdapat beberapa cara di dalamnya atau yang disebut dengan Figurasi, yang pada dasarnya merupakan bentuk mewujudkan mimpi. Cara yang dilakukan oleh tokoh utama dalam mewujudkan mimpinya adalah dengan mencari lembaran kosong yang sudah bekas atau sudah tidak terpakai, untuk digunakan sebagai kebutuhan mereka di Sekolah. Pencarian yang dilakukan oleh Kakak beradik ini, selalu pada tempat sampah. Mereka akan mencarinya ketika sepulang sekolah, membagi tempat pencarian, agar lebih mudah dalam mengumpulkan lembar-lembar bekas tersebut.

Novel yang berjudul Selembar itu Berarti karya Suryaman Amipiriono. Pengarang ingin memberikan pesan kepada pembaca bahwa, tidak ada mimpi yang tidak menjadi nyata, setiap mimpi sesorang tentu berbeda-beda. Akan tetapi, perjungan serta kerja keraslah yang dapat mendorong terwujudnya mimpi tersebut. Sebagaimana yang digambarkan pengarang dalam novel Selembar itu Berarti, tokoh utama Putri dan Diaz yang berusaha keras dalam mengejar mimpinya, bahkan tokoh Putri yang harus bekerja dikarenakan keterbatasan ekonomi, mecari lembaran kertas bekas untuk tetap bersekolah. Perilaku seperti inilah, yang patut untuk diteladai oleh generasi muda sekarang. Keulatan, usaha, serta kerja keras yang harus di contoh. Sehingga, kita generasi muda, mampu mewujudkan mimpi kita.

\section{DAFTAR PUSTAKA}


Ambaryani. (2018). Mimpi Tentang Masa Depan Dalam Karya Anak-Anak Kubu. Jurnal Studi Ganre dan Anak, 2(5), 155-161.

Assegaf, M.Y., Galib M., Wahid M. A. (2018). Sumber Mimpi Dalam Perspektif Hadis. Jurnal Diskursus Islam, 2(6), 343-357.

Bimo, W. (2012). Pengantar Psikologi Umum. Yogyakarta : Insan Cita.

Destari, H.P.I. (2008). Mimpi Tokoh Utama Prior Walker: Sebuah Rekonstruksi Identitas Gay dalam Drama Angels in America Karya Tony Kushner. Skripsi. Program Sudi Bahas Inggris. Universitas Indonesia.

Minderop, A. (2010). Psikologi Sastra. Karya sastra, Metode, Teori, dan Contoh Kasus. Jakarta: Yayasan Pustaka Obor Indonesia.Yudrik, J. (2011). Psikologi Perkembangan. Jakarta: Kencana

Nur, M. (2014). Metafisika Mimpi, Telaah Filsafati Terhadap Teori Mimpi
E.G. Jung (1875-1961). Laporan Penelitian. Program Pascasarjasana Universitas Gadja Mada, Yogyakarta.

Purwanto, M.N. (2007). Psikologi Pendidikan. Bandung: PT. Remaja Rosdakarya.

Qur'ani, H.B. (2019). Martabat Perempuan Minangkabau dalam Novel Tengelamnya Kapal Van Der Wijck Karya Hamka. Lingua Rima, 2(8), 1-9.

Sadulloh, U. (2006). Pengantar Filsafat Pendidikan. Bandung: CV. Alfabeta.

Santrock, J.W. (2008). Psikologi Pendidikan. Jakarta: Prenada Media Group.

Yuminah. (2018). Konsep Mimpi Dalam Perspektif Psikologi Islam: Studi Komparasi Psikologi Islam Dan Psikologi Barat. Jurnal Psikologi Islam, 2(5), 87-102. 